\title{
Siblings of a Different Kind: E-Government and E-Commerce
}

\author{
Karine Barzilai-Nahon and Hans Jochen Scholl \\ University of Washington, The Information School \\ $\{$ karineb, jscholl\} @uw. edu
}

\begin{abstract}
This paper reports on the last phase of a longitudinal exploratory study, which aims to compare similarities and differences between e-Commerce and e-Government. In two stages, we collected rich data via focus groups of experts from both public and private sectors. This paper reports on our findings in the areas of Process Management, Information Management, and Stakeholder Relations. We found the trajectories of the two phenomena of e-Commerce and e-Government to be quite distinct such that one can hardly serve as a role model for the other. Yet, comparing the two phenomena still unveils a high potential for cross-pollination.
\end{abstract}

\section{Introduction}

When we began this longitudinal exploratory study of similarities and differences between e-Commerce and e-Government in 2006 [3, 4, 31], we discovered that eCommerce and e-Government had fairly different drivers, priorities, and governing principles, while at the same time certain processes were similar. The main drivers studying the subject were the gap of literature and few studies which exist, that compare the two sectors. Also, a deeper understanding of the similarities and differences between e-Commerce and e-Government may lead to cross-fertilization and reduction of unnecessary reduplication in both sectors.

In this paper we present our detailed findings in three important areas of comparison (1) process management, (2) information management, and (3) stakeholder relations. This paper reports on three of then areas, which we studied in our longitudinal exploratory study. However, this does not imply that the other areas are of lesser importance. It is only due to space constraints that we refrain from presenting results in areas such as digital divides, citizen/customer focus, technology management, standardization, interoperability, human resources, and cost/benefits. We will present and discuss those findings elsewhere. However, the three areas mentioned above are central to the understanding of the similarities and differences of e-Commerce and eGovernment.

This paper is organized as follows. First, we briefly update the pertinent literature on e-Commerce and e-Government. Second, we introduce and discuss the study design followed by the presentation and discussion of our findings. We aim at creating a theoretical foundation for a later theory testing-oriented stage of research and present the theoretical development in the form of five topical clusters and sub-clusters. We 
conclude by discussing the implications of our findings for the better understanding of theory and practice.

\section{Review of Related Literatures}

The body of comparative literature on e-Commerce and e-Government has not grown much over the past few years. Except our own work [3, 4, 31], we found only one further study engaging in comparative analysis of the two phenomena [23]. However, that study based its analysis on surveying user perceptions of relative performance and functionality of US Federal Government websites versus commercial providers such as Google, Yahoo, MSN, CNN, and USAToday among others. As opposed to those authors, we were interested in identifying the drivers, motivations, challenges, and achievements of e-Government and e-Commerce from an internal and behindthe-scene perspective. For anticipating and isolating potential similarities and differences between e-Commerce and e-Government, we also looked at related streams of literature $[5,27,28]$.

On a more general plane, public-to-private differences have been identified in three areas: (1) environmental drivers and constraints, (2) organizational mandates and scope, and (3) internal processes, complexities, and incentives [28]. The private sector has been also praised for its higher agility, greater resourcefulness, less burdensome bureaucracy, and stronger motivation to proactively innovate when compared with public sector organizations $[6,27,28]$. These differences also surfaced in a study, which compared the strategic priorities of Chief Information Officers (CIOs) in both public and private sectors. It was found that public-sector CIOs focused on (a) the implementation of an IT architecture, (b) cultural change, (d) hiring/retaining skilled professionals, (e) and streamlining business processes, while private-sector CIOs emphasized (a) simplifying business processes, (b) improving services, (c) effective relationships with senior executives, (d) preventing intrusions, and (e) the implementation of IT architecture. Process change via streamlining and service improvement were more highly ranked by private-sector CIOs [34].

Further, the business models of e-Commerce and e-Government differ in significant ways: while the e-Commerce business model aims at creating customer value and at generating revenue, the e-Government business model is based on laws, statutes, and regulations providing citizens and firms with access to government information and services, and also delineating intergovernmental relationships, strategies, and interoperation of electronic government information systems (EGIS)[16], see also [32]. Citizens' acceptance of e-Government rests on trust, information access, public accessibility, quality of service, time saving, efficiency of service, and social awareness [25]. Also, in e-Commerce several sub-models may be found [7], which explain certain differences particularly in process management.

Finally, as our previous studies uncovered, similarities between e-Commerce and e-Government were found regarding (1) process improvements, (2) backend (process) integration, (3) cost savings, (4) information sharing, (5) vertical and horizontal systems integration, (6) increased responsiveness and service quality, (7) standardization efforts, and (8) the criticality of senior leadership support. Differences between the sectors were found to prevail regarding (1) the drivers and motivations for 
e-Commerce and e-Government, (2) stakeholder expectations, and (3) resource availability (4) concern regarding the digital divides [4, 31].

\section{Research Questions and Method}

Study Questions. Except for the few studies mentioned above, we had to deal with a rather thin base of knowledge in this particular area of research and could only incorporate an emergent theoretical framework, which was mostly derived from our own studies on the subject. This led us to follow through with our originally envisioned, two-stage exploratory research approach [2, 8, 26] addressing the two overarching research questions of

(R1) What is similar in private-sector e-Commerce and public-sector eGovernment, and how does it matter?

(R2) What is different in private-sector e-Commerce and public-sector eGovernment, and how does it matter?

Both e-Commerce and e-Government projects and implementations are engrained in institutional and social settings $[11,24]$ leading to a mesh of socio, technical, and organizational complexities, which defy the reduction of the study problem to a few variables. As a consequence, we opted for the empirical format of focus group discussions, which has proven highly effective in study situations of this kind $[9,13,14,20$, 21]. In focus groups, the interaction between participants can be expected to lead to rich data and high data quality [26]. In our study design, we incorporated two stages of data collection. In the first stage, we had sector experts discuss the overall research questions with other experts from the same sector. We compared the findings in each sector, and identified similarities and differences between the two sectors. The first stage entailed six focus groups with 17 individuals from the public sectors, and 18 from the private sectors. Based on this first stage analysis, we developed a theoretical model represented by a set of 29 propositions [31]. In the second stage, we presented the propositions we developed in the area of process management, information management-, and stakeholder-relations to a focus group which comprised three experts from each sector together. This second-stage focus group approach with experts from both sectors, we expected, would amend our insights and give us further clues regarding the soundness and validity of our initial theoretical concept which was derived from separate-sectored focus groups.

Sampling Method. The sampling had to be purposive [29], since certain criteria outlined below had to be met in order to qualify for meaningful data. We also stratified the sample using Anthony's framework, which distinguishes between professionals, supervisors with operational control, managers, and strategic planners [1] and chose the managerial level for the pilot, since that level appeared to us high enough for capturing strategic aspects and motives as well as low enough to identify specifics of implementation and outcomes. Individuals were selected on the basis of willingness to participate and on the basis of prior involvement in and experience with e-Commerce or e-Government projects. For both sectors, participants were selected from organizations in the US Pacific Northwest, which has been found 
highly developed in both e-Commerce (for example, Amazon.com, Boeing, Microsoft, etc.) and e-Government $[15,17,18]$. We recruited participants from different size and type of organizations and government entities. We did not allow any expert to participate twice, in order to get a better variation of perspectives. We required that the projects, in which the participants had been involved, had been of strategic nature to the organization. Also, the project had to contain a major transactional component. In the first stage of the exploration, six focus groups were conducted: three with participants from private sector, and three for participants from the public sector. In the second stage, when we confronted participants from both sectors with our study findings from the first stage, we conducted one focus group with six participants, three from each sector.

Data Collection. In the first-stage letter of invitation to prospective participants from the private sector, we verbally and graphically introduced the concepts of business-toconsumer (B2C), business-to-business (B2B), business-to-government (B2G), business-to-employee (B2E), and IEE. Likewise, we introduced the concepts of G2C, $\mathrm{G} 2 \mathrm{~B}, \mathrm{G} 2 \mathrm{G}$, and government-to-employee $(\mathrm{G} 2 \mathrm{E})$ as well as IEE in the invitation letters to prospective participants from the public sector. Intentionally, we framed and pre-structured the discussion in that way for systematic comparability. We continue to believe that this framing and pre-structuring would not hamper the expert discussion in any way, on the contrary. For all six groups we introduced the two dimensions of "informational" and "transactional." The six focus groups were conducted in pairs. They were organized as half-day focus group discussions with the selected participants, first with the private sector participants, the next day with the public sector participants. The moderator first introduced the focus group format to the participants; she then re-introduced the e-Commerce and e-Government concepts as already outlined in the invitation letters. She explained to participants that the first session would be dedicated to the "informational" aspects of the five concepts followed by a second session on the "transactional' aspects. The moderator then launched the focus group discussion with an opening question and facilitated the discussion, while three observers took notes and administered the audio recording [20]. In the second stage, we invited experts from both sectors who had not participated in the first stage of this study. As attachment to the invitation letter, we shared our publication [31], and indicated that we would focus on the three areas of process management, stakeholder relations, and information management. The second-stage session format comprised two 90-minute discussion sections spread over a half day. The propositions were read to participants, one at a time. Participants then engaged in discussing the proposition. Again, notes were taken, and the discussions were audio-recorded [20]. The audio tracks were transcribed yielding over 370 pages of transcripts for both stages. Also, over 170 pages of notes were taken.

Data Analysis. In this study we mainly used Strauss and Corbin's coding methodology [33]. In four passes, the transcripts and emerging concepts were analyzed. First, the four researchers independently read the transcripts identifying units of data. Our impression from the collection exercise was confirmed during this phase that we had in fact managed to collect rich and high-quality data in all four sessions. In the second pass, the two researchers read the transcripts again and consolidated the units of data. In an open coding process [33], each unit of data was then assigned to a preliminary 
category or sub-category whose dimensions and properties were developed from the data. New categories and sub-categories were introduced, in case existing categories did not apply [12]. Convergence and assignment of categories, which the two researchers had identified independently, was performed at each step of the data analysis. In the second stage, we conducted a qualitative convergence and gap/difference analysis between the findings from the first and second stage.

\section{Findings}

In this section, we present our findings the areas of (1) process management, (2) information management, and (3) stakeholder relations.

\subsection{Process Management}

\subsubsection{Process Streamlining and Process Integration}

In the first stage of our exploration, we found that e-Commerce information systems (ECIS) and e-Government information systems alike were more effective when processes were streamlined and new workflows were introduced. Also in both sectors, we found a trend in favor of modernizing and overhauling workflows and processes. Early projects in both sectors obviously only mimicked the existing processes leading to manumation (rather than automation) as some scoffers had put it [22]. However, after some low-hanging fruits had been harvested in this fashion, in both sectors it was recognized that process redesign and creation of new workflows would improve service quality, speed up service and the processing of transactions. As we found in the second stage of our exploration, the two extremes of mere mimicking and window-dressing of old processes, on the one hand, and radical redesigning, streamlining, and inventing of new processes, on the other hand, rarely, if ever, occurred in practice. For either sector, the two extremes should rather be understood as the two end points of a continuum, in which hybrids of some sort emerged with a tendency to move over time from the end of old processes towards the other end of new and streamlined processes and workflows. Time pressures in active projects, lack of resources including skilled labor, perceived high risks, concerns regarding manageability, and high cost were among the most frequently cited factors that were attributed to the fact that most e-projects initially appeared as redressed old workflows. On the other hand, when scouring for streamlining opportunities, in both sectors it was found that a number of workflows would not even require the utilization of technology.

Integration and alignment (see also 4.1.3) of processes and workflows between organizational units and across organizations also emerged as both a side effect, and in some cases, as a prerequisite for successful redesign and the launch of e-projects. In both sectors, we found cases where the redesign and streamlining of a process or workflow hinged upon another party's willingness to also adjust and streamline her processes. It was further reported from both sectors that during times of economic hardships and pressures, process alignment and integration efforts were more easily introduced and established than in times of ease.

Also, in the second stage participants from government confirmed earlier findings that process and workflow alignment was still a challenge due to various factors such as preventive statutes, regulations, and laws, or bureaucratic inertia, turf protection, or 
unwillingness to collaborate. Some technical obstacles such as media breaks or legal requirements also played a role in this regard. Yet, for successful transaction processing, a certain degree of process alignment and integration as well system interoperability on the basis of backend system integration was seen as indispensable.

\subsubsection{Transaction Processing}

Electronically processed transactions have become a cost-effective, speedy, and reliable method of conducting the business in both sectors. In government, most electronic transactions are still internal, while external online transactions involving citizens and businesses were believed to be not as sophisticated as in e-Commerce. In the private sector, transaction volumes with customers (B2C transactions) appeared to be much higher than those in the public sector with citizens (G2C transactions). We were not able to compare the actual transaction volumes in the two sectors or even give an informed estimate, since the amount of government-internal transactions (G2G transactions) is unknown at this point in time. In the second stage, participants also discussed in more detail the motivation for increasing the volumes of online transactions such as drastic cost savings, higher profit margins (in the private sector), improved customer/citizen profiling, improved service quality, speedier service provision, improved customer/citizen experience, more accurate and complete data entry, and with more accurate data for analysis.

In terms of a pleasing online service experience on part of the human actor, the private sector still appears to have an edge over the public sector, even though some governments seem to have narrowed the gap. Governments, it was said, cannot easily relinquish certain legacies (information systems as well as statutory and legal frameworks) as easily as private-sector firms can that are able to start a new business from scratch without such heritage.

Participants also remarked that the profiling-based customer-centric perspective, which is capable of singling out individual persons' preferences and dislikes as it has evolved in e-Commerce, might be even undesirable in e-Government. The publicsector equivalent it was said might draw connotations of Orwell's Big Brother ("While you are applying for this-and-that license, we are also finding that you have not yet paid the following traffic citations, which are overdue. Also, your pet license is expiring shortly. We can only service your request after you paid the traffic citations in full.").

However, for example, with reference to e-voting practices, particularly in Europe, or, the introduction of citizen self-services via kiosks, participants attributed to government the capability and successful implementation of innovative concepts. Also, shrinking budgets and citizens' increased service quality expectations seemed to have stimulated EGIS-based innovations in government, much like market competition does based on ECIS in the private sector. In other words, despite different drivers, in both e-Commerce and e-Government strong pressures exist, which force innovation to happen.

Another similarity between the e-Commerce and e-Government was seen in the growing data awareness in both sectors. Data-centric approaches when analyzing, for example, service quality and needs-oriented service offerings have been observed in both sectors. Participants expected that the open government and transparency initiatives, which governments on all levels and around the world began pursuing, would massively add to the data awareness and sophisticated use of data in both sectors. 


\subsubsection{Alignment and Collaboration}

In our first-stage exploration, we found collaboration and alignment in B2B and G2G scenarios to be critical to the success of improved service delivery (see also 4.1.1.). Interestingly, whenever effective intergovernmental collaboration was found it was more effective if voluntary rather than an imposed (hierarchical) collaboration. Also, similar organizational sizes and governance structures appeared to matter a lot. Moreover, the development of formal collaborative governance structures and formal agreements appeared to be essential to success, ideally on the basis of a shared vision and a common strategy. In the private sector, most collaborative endeavors appeared to rest on mutual and shared business interest. Both hierarchical (for example, vendorsupplier) and peer relationships were found in B2B collaboration. However, it could not be determined which type of relationship (hierarchical vs. peer) worked more effectively.

Our second-stage experts fully confirmed the earlier findings and also added important aspects. Independent of organizational sizes and governance structures they maintained data sharing had expanded almost exponentially in recent years in both sectors regardless of any mandates. However, the experts acknowledged the inherent complexity of alignment and collaboration, which permeates both organizational and technology-related levels. Interestingly, when it came to continued electronic collaboration, small businesses appear to be much less ready for system interoperation and electronic information exchanges than government agencies or larger private businesses.

Again we heard that similar organizational sizes and similar governance structures of prospective partners are (at least in government) favorable for collaboration, while dissimilarities in those areas can pose serious obstacles for collaboration. The alignment of strategic priorities was found to become stronger over time the more the collaboration was seen as effective and successful.

Finally, the experts in the second stage presented and discussed a number of examples within and across both sectors where collaboration on a voluntary basis seemed to work more effectively than when coerced like in a quasi-hierarchical relationship. In any case, formal agreements between collaborating parties including memoranda of understanding and service level agreements appear to be an important element of successful long-term collaborative efforts in both sectors. However, even for single projects, we found that a formal agreement defining the scope, timeline, cost, and projected outcome had been negotiated and signed.

\subsection{Information Management}

The subject of information management drew strong attention and discussions from participants. Particularly two main subjects appeared as significant: i) the impact of information quality on the interactions between companies or government agencies and their clients or citizens respectively; and ii) the role content management plays in the organizational/governmental life.

\subsubsection{Impact of Information Quality (IQ)}

The literature proposes eight major dimensions of information quality that needs to be addressed (1) accuracy, (2) comprehensiveness, (3) currency, (4) cognitive authority, 
(5) assurance/reliability, (6) relevance/precision/recall, (7) timeliness, and (8) perceived value [19]. In this study, we found evidence that indeed all eight criteria were important elements of high IQ. Access to information of high quality along those lines was portrayed as crucial to the success of e-projects in both government and commerce. While both sectors consider IQ as critical, and acknowledged the strong correlation between IQ and effective information management, few differences between the sectors surfaced.

First, maintenance of acceptable levels of information quality appeared to be more challenging in e-Government than in e-Commerce. Not only higher volumes of information appeared as a factor explaining the difference between the sectors, but also the possible error range, the status of the information (mandatory or voluntary) and the impact this information has on people. While in private sector people allow a certain degree of error range to occur (for example - delivery of your product to a different address), in the public sector these errors may have a deep impact on people (for example - a emergency call responder messing up with the location of call). The demand for ever-high IQ levels burdens and challenges the maintenance of the information. Also, in e-Commerce, strategic decisions about record keeping, for example, what types of information should be kept, may change according to strategic decisions of the organization. As opposed to the private sector, information may be required to be kept and archived for a long period of time in the public sector. Regulations may create constraints that enforce government agencies to maintain information in a certain way. Therefore, the mandatory facet of information keeping in government has straight implications on the complexity of maintenance. Finally, information quality had a direct major and critical impact on the life of people. Therefore, maintenance of the information will be similar to the careful record keeping process.

Second, the impact of information quality was raised again in the second-stage discussion when we presented our proposition derived from the literature and the first stage of the study that lower information quality affects e-Commerce more negatively than e-Government. This proposition stimulated a long debate, and participants thought that the contrary was true, that is, lower information quality more negatively affects e-Government than e-commerce. Participants perceived lower IQ to impact mainly economical and financial aspects companies in e-Commerce, while in eGovernment lower IQ was perceived as impacting the life of people in every possible way, for example, the way our identity is represented in public, reward and punishment of society and physical well-being.

\subsubsection{The Role of Content Management}

Document Life Management, the management of document flows, as well as the proper archiving of electronic records and removed web content along with previous versions of websites were mentioned repeatedly as major challenges in e-Government content management. We found that participants reported in both stages of the study that content management was more challenging in government than in the private sector due to volume of information and complexity of linked content. The complexity of the content management in the public sector as opposed to the private sector was related to two main aspects: i) the time aspect of keeping the data and its retrieval afterwards. The scope of government record keeping was very long on average. Moreover, in many cases it was not due for deletion. Content management it was said 
became more challenging due to the changing notions of public/private interests or contexts between the time of archiving and the time of retrieval. ii) the sensitive balance between freedom of information and privacy - in recent years there appeared to be a growing trend towards open government and more transparency. It sharpened the debate of what was considered private and what should be regarded public, and more specifically, which publicly held information would still need to be kept secret in order to balance other rights. Government agencies obviously seemingly tried to strike a balance between citizens' need for information and the extent of government services to provide that information electronically. This juggle made it difficult to strategize about content management, especially when the goal changed frequently and the public/private distinction had become so dynamic.

\subsection{Stakeholders Relations}

The subject of stakeholder relations appeared in both stages of the study in different variations. Participants agreed that governance of stakeholders was a critical component in the success or failure of projects and that the structure of governance influences ECIS and EGIS designs and deliverables both in e-Commerce and in e-Government. Disagreements appeared as to the effect the structure of this governance has. Moreover, we hypothesized that the process of convincing top-leadership to support and EGIS project is harder than in private sector. Participants from the public sector agreed that this was crucial in EGIS projects and very hard due to diverse needs, different weight and influence of stakeholders, and, in public sector, the difficulty to show a clear return on investments. Nevertheless, there was no consent about whether it was harder to win support from top-leadership for e-projects in either the public or the private sector.

In order to establish lasting governance structures in the public sector, the relationships among different types of stakeholders, elected and appointed officials, political and professional staff, and federal, state, and local stakeholders needed to be balanced according to the experts. This was harder to accomplish when the boundaries of the system were rigidly fixed for a long period, most of the professional staff was retained, the needs were vast and the interests were incongruent, or even pulling into different directions [10, 30]. For example, participants reported the fear to partner with "too big a city", and to create a dependency on that City's resources and governance structure. An important issue that surfaced in the second stage of the study was that although there were diverse stakeholders with whom agencies needed to deal, still the collaboration was more effective between institutions of similar size and similar governance structure. Finally, while diversity appeared as a critical issue also for the e-Commerce sector, we were not able to assess its exact impact.

\section{Discussion and Summary}

We set out to investigate, identify, and characterize the similarities and differences between e-Commerce and e-Government since we believed that the findings from such a study would benefit academic knowledge and e-Commerce and e-Government practice alike. In the following we discuss and summarize our observations and insights. 


\subsection{Similarities between E-Commerce and E-Government (Research Question \#1)}

According to our findings both ECIS and EGIS benefit their respective organizations significantly more when the underlying workflows and processes are not only electronic re-embodiments of their paper-based antecedents but rather streamlined, simplified, or completely discarded and replaced by different workflows and processes, which take full advantage of the technology. This seems to be increasingly understood in both commerce and government. We also found completely new workflows in both sectors, which would not have been possible without ECIS and EGIS.

A great incentive for streamlining and redesigning workflows and processes we found in the increased degree of collaboration within and between the sectors, which has become possible in an instantaneous fashion through ECIS and EGIS.

We further found that collaboration between partners within and across sectors works better when it unfolds on the basis of formal agreements. In government, it was noted that imposed collaboration works poorly as opposed to collaborative engagements based on freedom of choice.

Interestingly, cross-sector collaboration based on ECIS/EGIS reduces cost and speeds up the process on both ends even if the private-sector partner provides systems, infrastructure, and maintenance.

Along with transactional collaboration and integration we found increasing collaboration within and across sectors also in the area of information sharing. If collaboration thrives, we saw even the partial alignment of strategic objectives as a result. Information quality played a critical role in this context. A positive feedback between perceived IQ, information sharing, and the strength of the relationship seemed to exist.

We found in both sectors that similar governance structures of organizations influenced how collaborative ECIS and EGIS were designed. Remarkably, in both sectors the perceived needs of citizens (and customers, respectively) strongly influenced the designs of respective systems. In e-Commerce, organizations were interested in providing a social environment, which was conducive to a positive experience as a customer.

These findings suggest that ECIS/EGIS-related phenomena have important characteristics in common, which go beyond the mere technical resemblance of systems and methods. Process redesign practices might be a worthwhile subject of further study. Likewise, practices and principles of organizational and technical collaboration appear to provide valuable experiences to be shared.

\subsection{Differences between e-Commerce and e-Government (Research Question \#2)}

However, we also found formidable differences in practices, principles, and drivers between e-Commerce and e-Government. Transaction processing was found more sophisticated and of far higher volume in commerce than in government. On the other hand, information processing and management, including the archiving of electronic records we found much more developed in the public sector than with private firms. The drivers of innovation were different in e-Commerce and in e-Government; however, the pressures for organizational change, service innovation, and transformation 
towards more citizen-/customer centric way of conducting business were similarly strong. As a result, the overall sophistication of EGIS did not appear to lag behind ECIS by orders of magnitude. Both sectors also made increasingly elaborate use of historical data and data from transaction processing in order to optimize desired organizational outcomes. Lower information quality was found to lead to immediate and economically negative effects in both sectors. However, while low information quality directly impacts the bottom line of commercial organizations, in the public sector low IQ could have even more dramatic consequences for citizens and businesses alike. In other words, the impacts of low IQ might be even more devastating in the public sector than in the private sector. Still, governments struggled more than commercial organizations to maintain acceptable levels of information quality leading to far greater challenges, for example, in content management.

Interestingly, leadership in government appeared to be more supportive of (in particular, collaborative) e-projects than their commercial counterparts. It also appeared that collaborative structures in the public sector were markedly stronger than those in the private sector.

Overall, what we found different between e-Commerce and e-Government suggests that the two phenomena follow different trajectories despite many similarities and technical commonalities. One obvious explanation lies in the sector-specific differences, which produce different drivers also in this area. It will be interesting to analyze to what extent Enterprise Resource Planning (ERP) systems, which are increasingly introduced in government, may help align the trajectories between eCommerce and e-Government to a higher degree than we found in this study.

\subsection{Limitations and Future Research}

In our samples of participants from the two sectors and after the focus groups were conducted we found that e-Government experts on average were from higher levels in the organizational hierarchy than e-Commerce practitioners who were more technically versed. Our results, hence, may be skewed that they represent more strategic perspectives in e-Government and more operational/tactical perspectives in eCommerce.

We also recognize that what we present here is the result of an exploratory study based on a limited number of participants. Our study attempts to lay theoretical foundations for more quantitatively oriented research on the subject, which we hope will lead us to more generalizable results. Furthermore in this paper we present results from three major (of eight) areas of analysis.

\section{References}

[1] Anthony, R.N.: Planning and control systems; a framework for analysis. Division of Research, Graduate School of Business Administration, Harvard University, Boston (1965)

[2] Arthur, S., Nazroo, J.: Designing fieldwork strategies and materials. In: Ritchie, J., Lewis, J. (eds.) Qualitative research practice: a guide for social science students and researchers, pp. 109-137. Sage Publications, Thousand Oaks (2003)

[3] Barzilai-Nahon, K., Scholl, H.J.: Comparing E-Government with E-Business Challenges. In: Internet Research (IR 8.0) Conference, Vancouver, BC/Canada, pp. 1-10 (2007) 
[4] Barzilai-Nahon, K., Scholl, H.J.: Similarities and differences of e-Commerce and e-Government: Insights from a pilot study. In: Sprague, R. (ed.) 40th Hawaii International Conference on System Sciences (HICSS40), pp. 92c(1-10). IEEE, Waikoloa (2007)

[5] Boyne, G.A.: Public and private management: What's the difference? Journal of Management Studies 39, 97-122 (2002)

[6] Bozeman, B., Bretschneider, S.: Public management information systems: Theory and prescriptions. Public Administration Review 46, 475-489 (1986)

[7] Chang, Y.-P., Yan, J.: Positioning In a New Dynamic E-Commerce Business Model. In: 3rd International Conference on Wireless Communications, Networking and Mobile Computing (WICOM 2007), pp. 3592-3595. IEEE, Shanghai (2007)

[8] Creswell, J.W.: Educational research: planning, conducting, and evaluating quantitative and qualitative research, 2nd edn. Merrill, Upper Saddle River (2005)

[9] Finch, H., Lewis, J.: Focus groups. In: Ritchie, J., Lewis, J. (eds.) Qualitative research practice: a guide for social science students and researchers, pp. 170-198. Sage Publications, Thousand Oaks (2003)

[10] Flak, L.S., Nordheim, S.: Stakeholders, Contradictions and Salience: An Empirical Study of a Norwegian G2G Effort. In: Proceedings of the 39th Annual Hawaii International Conference on System Sciences (HICSS39 e-Government Track), vol. 4, pp. 75a-75tig. IEEE, Kauai (2006)

[11] Giddens, A.: The constitution of society: outline of the theory of structuration. University of California Press, Berkeley (1984)

[12] Gorman, G.E., Clayton, P., Rice-Lively, M.L., Gorman, L.: Qualitative research for the information professional: a practical handbook. Library Association Publishing, London (1997)

[13] Greenbaum, T.L.: The handbook for focus group research, 2nd edn. Sage Publications, Thousand Oaks (1998)

[14] Greenbaum, T.L.: Moderating focus groups: a practical guide for group facilitation. Sage Publications, Thousand Oaks (2000)

[15] Ho, A.T.-k.: Reinventing local governments and the e-government initiative. Public Administration Review 62, 434-444 (2002)

[16] Janssen, M., Kuk, G., Wagenaar, R.W.: A survey of Web-based business models for e-government in the Netherlands. Government Information Quarterly 25, 202-220 (2008)

[17] Kaylor, C.H., Deshazo, R., Van Eck, D.: Gauging e-government: A report on implementing services among American cities. Government Information Quarterly 18, 293-307 (2002)

[18] Kaylor, C.H.: The next wave of e-Government: The challenges of data architecture. Bulletin of the American Society for Information Science and Technology 31, 18-22 (2005)

[19] Klischewski, R., Scholl, H.J.: Information Quality as the Capstone of E-government Integration, Interoperation, and Information Sharing. Electronic Government, an International Journal 5, 203-225 (2008)

[20] Krueger, R.A., Casey, M.A.: Focus groups: a practical guide for applied research, 3rd edn. Sage Publications, Thousand Oaks (2000)

[21] Madriz, E.: Focus groups in feminist research. In: Denzin, N.K., Lincoln, Y.S. (eds.) Handbook of qualitative research, 2nd edn., pp. 835-850. Sage Publications, Thousand Oaks (2000)

[22] Mohan, L., Holstein, W.K.: EIS: it can work in the public sector. MIS Quarterly 14, 434-448 (1990) 
[23] Morgeson, F.V., Mithas, S.: Does E-Government measure up to E-Business? Comparing end user perceptions of U.S. Federal Government and E-Buisness web sites. Public Administration Review 69, 740-752 (2009)

[24] Orlikowski, W.J., Robey, D.: Information technology and the structuring of organizations. Information Systems Research 2, 143-169 (1991)

[25] Park, R.: Measuring Factors That Influence the Success of E-government Initiatives. In: Proceedings of the 41st Annual Hawaii International Conference on System Sciences (HICSS '08), pp. 218 (1-10), IEEE Computer Society Conference Publishing Services, Waikoloa (2008)

[26] Patton, M.Q.: Qualitative research and evaluation methods, 3 ed. Sage Publications, Thousand Oaks (2002)

[27] Perry, J.L., Rainey, H.G.: The public-private distinction in organization theory: A critique and research strategy. Academy of Management Review 13, 182-201 (1988)

[28] Rainey, H., Backoff, R., Levine, C.: Comparing public and private organizations. Public Administration Review 36, 233-244 (1976)

[29] Ritchie, J., Lewis, J., Gillian, E.: Designing and selecting samples. In: Ritchie, J., Lewis, J. (eds.) Qualitative research practice: a guide for social science students and researchers, pp. 77-108. Sage Publications, Thousand Oaks (2003)

[30] Scholl, H.J.: Applying stakeholder theory to e-government: benefits and limits. In: Schmid, B., Stanoevska-Slabeva, K., Tschammer, V. (eds.) 1st IFIP Conference on E-Commerce, E-Business, and E-Government (I3E 2001), pp. 735-747. Kluwer, Zurich (2001)

[31] Scholl, H.J., Barzilai-Nahon, K., Ahn, J.-H., Popova, O.H., Re, B.: E-Commerce and e-Government: How Do They Compare? What Can They Learn From Each Other? In: Proceedings of the 42nd Annual Hawaii International Conference on System Sciences (HICSS '09), Waikoloa, Big Island, Hawaii, pp. 141 (1-10) (2009)

[32] Stahl, B.C.: The Paradigm of E-Commerce in E-Government and E-Democracy. In: Huang, W., Siau, K., Wei, K.K. (eds.) Electronic Government Strategies and Implementation, pp. 1-19. Idea Group Publishing, Hershey (2005)

[33] Strauss, A.L., Corbin, J.M.: Basics of qualitative research: techniques and procedures for developing grounded theory, 2nd edn. Sage Publications, Thousand Oaks (1998)

[34] Ward, M., Mitchell, S.: A comparison of the strategic priorities of public and private sector information resource executives. Government Information Quarterly 21, 284-304 (2004) 